\title{
Postoperative analgesia with pericapsular nerve group (PENG) block for primary total hip arthroplasty: a retrospective study
}

\author{
Kiran Mysore, MD $\cdot$ Sushil A. Sancheti, MD FRCPC $\cdot$ Steven R. Howells, MD \\ FRCPC $\cdot$ Erin E. Ballah, MSc $\cdot$ Jennifer L. Sutton, MN $\cdot$ Vishal Uppal, MBBS \\ MSc FRCA
}

Received: 25 May 2020/Revised: 12 June 2020/Accepted: 6 July 2020 / Published online: 13 July 2020

(c) Canadian Anesthesiologists' Society 2020

\section{To the Editor,}

The pericapsular nerve group (PENG) block, which targets sensory branches of the obturator, accessory obturator, and femoral nerves in the anterior capsule of the hip, has been proposed as an effective method to treat pain associated with hip fractures and total hip arthroplasty (THA). ${ }^{1}$ The PENG block provides coverage of the sensory nerves supplying the anterior hip ${ }^{2}$ while sparing motor blockade of the quadriceps; a known complication of fascia iliaca and femoral blocks. ${ }^{3}$ We began an Enhanced Recovery After Surgery program for joint arthroplasty in September 2018 and the PENG block was introduced in an attempt to improve quality of recovery. A survey of the American Association of Hip and Knee Surgeons showed periarticular local infiltration anesthesia (LIA) is used in $80.3 \%$ of THA patients. ${ }^{4}$ We anticipated that adding a PENG block to LIA, rather than replacing it, would gain easier acceptance from both surgeons and anesthesiologists. We present the findings of our retrospective review that compares the analgesic benefit of adding PENG block to LIA and multimodal analgesia in THA.

K. Mysore, MD · S. A. Sancheti, MD FRCPC $(\bowtie) \cdot$

S. R. Howells, MD FRCPC

Department of Anesthesia, Memorial University, St. John's, NL, Canada

e-mail: sancheti@me.com

E. E. Ballah, MScJ. L. Sutton, MN

Perioperative Division, Eastern Health, St. John's, NL, Canada

V. Uppal, MBBS MSc FRCA

Department of Anesthesia, Perioperative Medicine and Pain

Management, Dalhousie, Halifax, NS, Canada
After Newfoundland and Labrador Human Research Ethics Board approval in November 2019, an historical cohort study was conducted among all patients who had THA from October 2018 to October 2019 at the Health Sciences Centre in St. John's, Newfoundland, Canada. Published research suggested periarticular infiltration reduced 24-hr hydromorphone consumption from 43.3 to $28.5 \mathrm{mg}$ (pooled standard deviation [SD], 22). ${ }^{5}$ A study with 36 participants per group would detect a difference of this size with probability of alpha and beta errors of 0.05 and 0.20 , respectively. We chose a time interval that included at least 36 completed PENG blocks. Patients with preoperative opioid tolerance, or those who received intrathecal morphine, fascia iliaca block, or postoperative epidural infusion were excluded.

We identified 123 patients who met the inclusion criteria; 47 received and 76 did not receive PENG block. The data for all eligible patients was retrieved from the anesthesia charting system and their electronic medical record. The PENG block was performed as in the original description ${ }^{1}$ by injecting $20 \mathrm{~mL}$ of $0.25 \%$ bupivacaine with 1:200,000 epinephrine and $2 \mathrm{mg}$ of dexamethasone between the psoas tendon and pubic ramus, under ultrasound guidance. Surgeons provided LIA $(20-40 \mathrm{~mL}$ of $0.25 \%$ bupivacaine with epinephrine) for all patients. All patients received intravenous patient-controlled hydromorphone, acetaminophen (3-4 g daily), and a nonsteroidal anti-inflammatory drug if co-existing medical conditions allowed.

Patient characteristics and outcomes are shown in the Table. The mean (SD) 24-hr postoperative hydromorphone equivalent consumption was lower in those receiving PENG blocks [4.5 (2.9) $\mathrm{mg}$ ] than those who did not [6.9 (5.5) $\mathrm{mg}](P=0.002)$. Those receiving PENG blocks were 
Patient characteristics and outcomes for first $24 \mathrm{hr}$

\begin{tabular}{|c|c|c|c|c|}
\hline Variables & $\begin{array}{l}\text { PENG block + LIA } \\
(n=47)\end{array}$ & $\begin{array}{l}\text { LIA } \\
(n=76)\end{array}$ & $\begin{array}{l}\text { Mean difference }(95 \% \\
\text { confidence interval) }\end{array}$ & $P$ value \\
\hline Female $n /$ total $n(\%)$ & $26(55 \%)$ & $44(58 \%)$ & & $0.78^{\mathrm{a}}$ \\
\hline Age (yr) & 64 (12) & $60(12)$ & & $0.048^{\mathrm{b}}$ \\
\hline BMI $\left(\mathrm{kg} \cdot \mathrm{m}^{-2}\right)$ & $32(6)$ & $33(7)$ & & $0.80^{\mathrm{b}}$ \\
\hline Spinal anesthesia ${ }^{\mathrm{d}}$ & $28(60 \%)$ & $24(32 \%)$ & $\mathrm{n} / \mathrm{a}$ & $0.002^{\mathrm{a}}$ \\
\hline Parenteral hydromorphone equivalents (mg) & $4.5(2.9)$ & $6.9(5.5)$ & $-2.4(-3.9$ to -0.9$)$ & $0.002^{\mathrm{b}}$ \\
\hline Average $\dagger$ pain scores at rest & $0.86(0.9)$ & $1.1(1.0)$ & $-0.25(-0.6$ to 0.1$)$ & $0.13^{\mathrm{b}}$ \\
\hline Average $\uparrow$ pain scores with activity & $1.9(1.6)$ & $2.1(1.4)$ & $-0.15(-0.7$ to 0.4$)$ & $0.59^{\mathrm{b}}$ \\
\hline Peak pain score at rest & $1.9(1.5)$ & $2.5(1.7)$ & $-0.57(-1.2$ to 0.0$)$ & $0.054^{\mathrm{b}}$ \\
\hline Peak pain score with activity & $3.8(2.6)$ & $4.0(1.7)$ & $-0.19(-1.0$ to 0.7$)$ & $0.66^{\mathrm{b}}$ \\
\hline Length of stay (hr) & $77[53-81]$ & $55[52-78]$ & $\mathrm{n} / \mathrm{a}$ & $0.09^{c}$ \\
\hline
\end{tabular}

All numbers are $n /$ group $\mathrm{N}(\%)$, mean $(\mathrm{SD})$, or median [interquartile range]

${ }^{\mathrm{a}}$ Chi squared; ${ }^{\mathrm{b}}$ Welch $\mathrm{T}$ test; ${ }^{\mathrm{c}}$ Mann-Whitney $\mathrm{U}$ test; ${ }^{\mathrm{d}} 2 \times 2$ ANOVA, Anesthesia $*$ PENG F $=0.036, P=0.85$

${ }^{\dagger}$ Averaged across first $24 \mathrm{~h}$

ANOVA = analysis of variance; $\mathrm{BMI}=$ body mass index; LIA = local infiltration analgesia; $\mathrm{n} / \mathrm{a}=$ not available; $\mathrm{PENG}=$ pericapsular nerve group; $\mathrm{SD}=$ standard deviation

also more likely to receive spinal anesthesia. A $2 \times 2$ factorial analysis of variance revealed no interaction between spinal anesthesia and PENG block on hydromorphone consumption. Secondary outcomes (length of stay, peak pain scores, and average pain scores at rest and with activity) were not significantly different between the two groups.

We found that PENG block was associated with a $2.4 \mathrm{mg}$ (95\% confidence interval, -3.9 to -0.89$)$ reduction in 24-hr hydromorphone consumption among patients receiving LIA following THA. Prospective randomizedcontrolled trials are required to confirm if this reduction in opioid consumption is associated with improvements in patient-centred outcomes, such as nausea/vomiting, satisfaction, and quality of recovery.

Acknowledgements We would like to thank the office of research, Department of Anesthesia, Perioperative Medicine and Pain Management, Dalhousie University, Nova Scotia, Canada for providing statistical funding support, and Dr. Sean P. Mackinnon, $\mathrm{PhD}$, Department of Psychology and Neuroscience, Dalhousie University for his input in the statistical analysis and interpretation of this study.

Disclosures None.

Funding statement None.
Editorial responsibility This submission was handled by Dr. Hilary P. Grocott, Editor-in-Chief, Canadian Journal of Anesthesia.

\section{References}

1. Giron-Arango L, Peng PW, Chin KJ, Brull R, Perlas A. Pericapsular nerve group (PENG) block for hip fracture. Reg Anesth Pain Med 2018; 43: 859-63.

2. Tran J, Agur A, Peng P. Is pericapsular nerve group (PENG) block a true pericapsular block? Reg Anesth Pain Med 2019; DOI: 10.1136/rapm-2018-100278.

3. Swenson JD, Davis JJ, Stream JO, Crim JR, Burks RT, Greis PE. Local anesthetic injection deep to the fascia iliaca at the level of the inguinal ligament: the pattern of distribution and effects on the obturator nerve. J Clin Anesth 2015; 27: 652-7.

4. Hannon CP, Keating TC, Lange JK, Ricciardi BF, Waddell BS, Della Valle $C J$. Anesthesia and analgesia practices in total joint arthroplasty: a survey of the American Association of Hip and Knee Surgeons membership. J Arthroplasty 2019; 34: 2872-7.e2.

5. Busch CA, Whitehouse MR, Shore BJ, MacDonald SJ, McCalden $R W$, Bourne RB. The efficacy of periarticular multimodal drug infiltration in total hip arthroplasty. Clin Orthop Relat Res 2010; 468: 2152-9.

Publisher's Note Springer Nature remains neutral with regard to jurisdictional claims in published maps and institutional affiliations. 